\title{
Analisis Pendapatan Usahatani Padi dan Perbandingannya Dengan Garis Kemiskinan di Desa Moyo Kecamatan Moyo Hilir
}

\author{
Muhammad Nurjihadi* \\ *Program Studi Ekonomi Pembangunan Universitas Teknologi Sumbawa (UTS) \\ Email:m.nurjihadi@uts.ac.id
}

\begin{abstract}
Abstrak
Penelitian ini bertujuan untuk mengetahui tingkat pendapatan petani padi di Desa Moyo Kecamatan Moyo Hilir dan membandingkannya dengan beberapa indikator garis kemiskinan sebagai ukuran untuk menilai tingkat kesejahteraan petani padi. Penelitian ini menggunakan metode campuran (kuantitatifkualitatif) yang disajikan secara deskriptif dan pengumpulan datanya di lakukan dengan teknik observasi serta wawancara. Penentuan responden dilakukan dengan teknik quota sampling. Analisis data dilakukan dengan teknik triangulasi. Hasil penelitian menunjukkan bahwa Rata-rata total pendapatan per kapita per bulan keluarga petani padi di Desa Moyo Hilir adalah Rp653.861,-Angka ini lebih rendah dari nilai garis kemiskinan menurut Bank Dunia yakni Rp758.100,tetapi lebih tinggi dari garis kemiskinan Sajogyo sebesar Rp266.667,-. Adapun jumlah petani padi yang berada dibawah garis kemiskinan menurut Bank Dunia adalah 73,3\%, sedangkan jumlah petani padi miskin menurut indikator garis kemiskinan Sajogyo adalah 6,7\%.
\end{abstract}

Kata kunci : Pendapatan Usahatani, Petani Padi, Garis Kemiskinan

\section{A. Latar Belakang}

Sektor pertanian adalah salah satu penopang perekonomian nasional dimana kontribusi sektor ini terhadap PDB pada tahun 2015 mencapai 13,45\% dan mampu menyerap tenaga kerja hingga 32\%. Salah satu komoditas pertanian yang paling banyak diusahakan oleh petani adalah tanaman pangan, terutama komoditas padi yang kontribusinya terhadap PDB Sektor pertanian mencapai 25,54\% pada tahun 2015 (BPS, 2016). Banyaknya pekerja yang menggantungkan hidupnya pada sektor pertanian menyebabkan sektor ini memberi kontribusi cukup signifikan terhadap kemiskinan. Oleh karenanya, diperlukan upaya pengukuran untuk menilai apakah petani mendapatkan penghasilan yang layak dari usahataninya.

Tingkat pendapatan petani secara umum dipengaruhi oleh beberapa komponen yaitu : jumlah produksi, harga jual, dan biaya-biaya yang dikeluarkan petani dalam usaha pertaniannya (Haryanti et al, 2009). Selain itu, Nurjihadi (2016) menyebutkan bahwa pendapatan petani juga disebabkan oleh beberapa faktor sosiologis lainnya seperti status atau posisi tawar petani dalam pasar, akses dan sumber permodalan, serta aspek kelembagaan petani. Posisi tawar yang rendah, minimnya akses terhadap sumber modal, serta lemahnya 
kelembagaan petani dapat menyebabkan petani terjebak dalam lingkaran setan kemiskinan (the vicious circle of poverty).

Ukuran kemiskinan yang dipakai di Indonesia mengacu pada indikator yang dikembangkan oleh Sajogyo dan disempurnakan oleh Badan Pusat Statistik (BPS) yang didasarkan pada konsep kecukupan gizi. Menurut Sajogyo, seseorang dikatakan miskin jika dia mengkonsumsi kurang dari 2.100 kilokalori aau setara dengan $320 \mathrm{Kg}$ beras per kapita per tahun (Agusta, 2016). Sedangkan secara global, kemiskinan diukur dengan menggunakan indikator Bank Dunia yang mendasarkan analisisnya pada jumlah pengeluaran per kapita per hari, yakni US\$1,90 per kapita per hari (Bank Dunia, 2013).

Kecamatan Moyo Hilir merupakan salah satu kecamatan di Kabupaten Sumbawa dengan jumlah penduduk yang bekerja di sektor pertanian pada tahun 2010 mencapai 77,86\%. Sementara itu, luas panen untuk tanaman padi pada tahun 2011 di kecamatan ini berjumlah 8.084 hektar dengan produktifitas 53,27 (kw/ha) dengan produksi keseluruhan 43.063 ton (BPS Sumbawa, 2012). Dengan banyaknya masyarakat yang bekerja di sektor pertanian serta luasnya areal panen padi ide kecamatan ini, diperlukan pengukuran untuk menilai apakah tingkat pendapatan petani padi di wilayah ini berada diatas atau di bawah garis kemiskinan.

\section{B. Literatur Review}

Pendapatan merupakan salah satu indikator untuk mengukur kesejahteraan seseorang atau masyarakat sehingga pendapatan masyarakat ini mencerminkan kemajuan ekonomi suatu masyarakat. Menurut Sukirno (2000), pendapatan individu merupakan pendapatan yang diterima seluruh rumah tangga dalam perekonomian dari pembayaran atas penggunaan faktorfaktor produksi yang dimilikinya dan dari sumber lain. Menurut Sukirno (2006) pendapatan adalah jumlah penghasilan yang diterima oleh penduduk atas prestasi kerjanya selama satu periode tertentu, baik harian, mingguan, bulanan maupun tahunan. Kegiatan usaha pada akhirnya akan memperoleh pendapatan berupa nilai uang yang diterima dari penjualan produk yang dikurangi biaya yang telah dikeluarkan.

Menurut Soekartawi (2006) dalam proses produksi terdapat biaya yang harus dikeluarkan untuk memperoleh hasil yang maksimal. Biaya yang dikeluarkan antara lain : 
a. Biaya Tetap (Fixed Cost)

Biaya yang tidak ada kaitannya dengan jumlah barang yang diproduksi. Biaya tetap tidak habis digunakan dalam satu masa produksi.

Contohnya : sewa tanah, pajak dan pembelian alat-alat.

b. Biaya Tidak Tetap (Variabel Cost)

Biaya yang besar kecilnya dipengaruhi oleh produksi. Biaya ini ada apabila ada sesuatu barang yang diproduksi.

Contohnya : Biaya Saprodi (benih, pupuk, pestisida)

c. Biaya Total (Total Cost)

Keseluruhan biaya tetap produksi yang diperoleh dari penjumlahan total biaya tetap dan biaya variabel.

Pendapatan terdiri dari pendapatan kotor dan pendapatan bersih. Menurut Soekartawi (2006), pendapatan kotor adalah pendapatan yang diperoleh dari usahatani selama satu periode usahatani, yang diperhitungkan dari hasil penjualan dan pertukaran. Adapun pendapatan bersih usahatani (Net Farm Income) merupakan keuntungan yang dapat dipakai untuk membandingkan beberapa alternative usahatani.

Chamber (1987) dalam Rudi (2013) mendefinisikan dua macam situasi kemiskinan: pertama, kemiskinan yang disebabkan oleh keadaan yang jauh terpencil atau tidak memadai sumber daya atau karena kedua-duanya sementara, kedua kemiskinan merupakan suatu keadaan masyarakat yang didalamnya terdapat ketimpangan yang mencolok antara orang kaya dan orang miskin. Kemiskinan sesungguhnya merupakan konsekuensi dari suatu struktural masyarakat dengan penduduk yang sangat padat, terbatasnya budaya, terbatasnya akses-akses terhadap barang konsumsi tingkat kesehatan yang rendah dan kesempatan pendidikan yang tidak merata.

Lebih lanjut Sharp, et al (1996) dalam Mudrajad Kuncoro (2004) mengidentifikasi penyebab kemiskinan dipandang dari sisi ekonomi. Pertama, secara mikro, kemiskinan muncul karena adanya ketidaksamaan pola kepemilikan sumber daya. Kedua, kemiskinan muncul akibat perbedaan dalam kualitas sumber daya manusia. Ketiga, kemiskinan muncul akibat perbedaan akses modal. 
Sementara itu, Ashari (2006) menyatakan bahwa kemiskinan yang terjadi dipedesaan disebabkan oleh rendahnya produktivitas pertanian, dimana rendahnya produktivitas pertanian itu sendiri disebabkan karena keterbatasa modal yang dimiliki oleh petani.

Kemiskinan umumnya diukur dengan menggunakan indikator atau kriteria garis kemiskinan (poverty line). Adapun setiap negara atau lembaga memiliki kriteria atau ukuran garis kemiskinan yang berbeda-beda. Bank Dunia (2013) menetapkan garis kemiskinan berdasarkan pengeluaran sebesar \$ 1,90 per kapita per hari yang berarti bahwa setiap orang yang pengeluarannya kurang dari angka tersebut dalam satu hari merupakan kelompok masyarakat miskin. Sementara itu, di Indonesia dikenal Garis Kemiskinan Sajogyo yang menggunakan pendekatan Kilokalori sebagai indikator garis kemiskinan dimana penduduk yang masuk kategori miskin adalah penduduk yang tidak mampu membeli kebutuhan makanan untuk mencukupi kebutuhan gizi sebesar 2.100 kilokalori per orang per hari atau setara dengan beras $320 \mathrm{~kg}$ per orang per tahun (Agusta, 2016). Konsep Sajogyo ini kemudian dimutakhirkan oleh Badan Pusat Statistik (BPS) dengan menetapkan garis kemiskinan tidak hanya pada aspek pangan dan gizi, tapi juga kemampuan untuk memenuhi kebutuhan dasar non makanan seperti pendidikan, perumahan, sandang, dan kesehatan. Garis kemiskinan Bank Dunia dan Sajogyo akan dipakai dalam penelitian ini, sedangkan garis kemiskinan BPS tidak digunakan mengingat sulitnya melakukan perhitungan garis kemiskinan dengan pendekatan pemenuhan kebutuhan dasar makanan dan non makanan karena keterbatasan data.

\section{Metode Penelitian}

Desain penelitian ini menggunakan metode campuran antara penelitian kualitatif dan kuantitatif yang dianalisa dan disajikan secara deskriptif. Proses pengumpulan data dalam penelitian ini menggunakan teknik teknik survey, yaitu dengan mengumpulkan data dari sejumlah individu dalam waktu bersamaan untuk menggambarkan keadaan populasi dengan menggunakan daftar pertanyaan terstruktur (kuisioner) yang telah dipersiapkan sebelumnya. Responden dalam penelitian ini berjumlah 50 orang yang dipilih dengan menggunakan teknik quota sampling. Analisis data dilakukan dengan teknik triangulasi data yang menggabungkan hasil analisa dari observasi lapangan, hasil pengumpulan data melalui wawancara, serta penelusuran dokumen yang relevan. Adapun data hasil wawancara dianalisis menggunakan rumus berikut: 
1. Untuk mengetahui pendapatan petani digunakan rumus:

$$
\begin{gathered}
\Pi=T R-T C \\
\mathrm{TR}=\mathrm{P} \times \mathrm{Q} \\
\mathrm{TC}=\mathrm{FC}+\mathrm{VC}
\end{gathered}
$$

dimana :

$\pi \quad=$ Keuntungan Usahatani

TR $=$ Penerimaan Total

$\mathrm{TC}=$ Biaya Total

$\mathrm{P} \quad=$ Harga Jual padi

$\mathrm{Q} \quad=$ Jumlah produksi padi

$\mathrm{FC} \quad=$ Biaya Tetap

$\mathrm{VC}=$ Biaya variabel

2. Hasil analisis pendapatan diatas dibandingkan dengan standar garis kemiskinan versi Sajogyo dan Bank Dunia. Adapun standar Sajogyo adalah setara dengan harga pasar dari $320 \mathrm{Kg}$ beras per kapita per tahun yang dikonversi menjadi per bulan, sedangkan standar Bank Dunia adalah pengeluaran US\$ 1,90 per kapita per hari yang dikonversi menjadi per bulan.

\section{Pembahasan}

\section{Keuntungan Usahatani Padi dan Tingkat Produktifitas Petani}

Dalam konteks usahatani padi di Desa Moyo Hilir, fix cost (biaya tetap) terdiri dari komponen sewa lahan, sementara komponen biaya lainnya seperti pemupukan, pengobatan, tenaga kerja, panen, penyiangan, dan sebagainya termasuk biaya variabel. Meski demikian, seluruh responden yang menjadi objek penelitian dalam penelitian ini merupakan petani pemilik sehingga tidak memerlukan biaya sewa lahan. Oleh karenanya, biaya tetap berupa sewa lahan dalam penelitian ini tidak dihitung mengingat tidak tersedianya data dari responden. Perkiraan biaya sewa lahan tidak dapat dilakukan mengingat tidak ada satupun responden yang bisa memperkirakan berapa biaya sewa lahan jika lahan yang mereka gunakan untuk menanam padi itu bukan milik mereka. Dengan demikian, komponen total biaya dalam penelitian ini sepenuhnya merupakan biaya variabel. 
Dengan kondisi tersebut, didapatkan hasil perhitungan keuntungan usahatani padi di Desa Moyo Hilir sebagaimana terangkum dalam tabel berikut:

Tabel 1. Analisa Usahatani Padi di Desa Moyo Hilir, Kecamatan Moyo Kabupaten Sumbawa

\begin{tabular}{|c|c|c|c|c|}
\hline Responden & $\begin{array}{c}\text { Luas Lahan } \\
\text { (Hektar) }\end{array}$ & $\begin{array}{l}\text { Total Cost } \\
\text { (TC) }\end{array}$ & $\begin{array}{c}\text { Total } \\
\text { Revenue (TR) }\end{array}$ & Keuntungan ( $\pi)$ \\
\hline Responden 1 & 1 & Rp5.090.000 & Rp19.800.000 & Rp14.710.000 \\
\hline Responden 2 & 8 & Rp4.545.000 & Rp6.720.000 & Rp2.175.000 \\
\hline Responden 3 & 0,25 & Rp4.655.000 & Rp7.920.000 & Rp3.265.000 \\
\hline Responden 4 & 1 & Rp3.872.000 & Rp16.800.000 & Rp12.928.000 \\
\hline Responden 5 & 0,5 & Rp3.145.000 & Rp8.750.000 & Rp5.605.000 \\
\hline Responden 6 & 0,25 & Rp2.900.000 & Rp6.800.000 & Rp3.900.000 \\
\hline Responden 7 & 0,075 & Rp1.320.000 & Rp1.920.000 & Rp600.000 \\
\hline Responden 8 & 1 & Rp1.700.000 & Rp7.200.000 & Rp5.500.000 \\
\hline Responden 9 & 1 & Rp3.995.000 & Rp7.000.000 & Rp3.005.000 \\
\hline Responden 10 & 1 & Rp4.510.000 & Rp27.000.000 & Rp22.490.000 \\
\hline Responden 11 & 1 & Rp5.250.000 & Rp10.800.000 & Rp5.550.000 \\
\hline Responden 12 & 1 & Rp2.950.000 & Rp15.120.000 & Rp12.170.000 \\
\hline Responden 13 & 1 & Rp1.754.000 & Rp7.200.000 & Rp5.446.000 \\
\hline Responden 14 & 0,3 & Rp4.690.000 & Rp10.080.000 & Rp5.390.000 \\
\hline Responden 15 & 0,3 & Rp4.260.000 & Rp9.720.000 & Rp5.460.000 \\
\hline Responden 16 & 0,25 & Rp3.695.000 & Rp7.560.000 & Rp3.865.000 \\
\hline Responden 17 & 0,25 & Rp3.355.000 & Rp7.560.000 & Rp4.205.000 \\
\hline Responden 18 & 1 & Rp9.520.000 & Rp30.240.000 & Rp20.720.000 \\
\hline Responden 19 & 0,3 & Rp4.645.000 & Rp9.360.000 & Rp4.715.000 \\
\hline Responden 20 & 0,2 & Rp3.217.000 & Rp6.660.000 & Rp3.443.000 \\
\hline Responden 21 & 0,5 & Rp3.210.000 & Rp15.300.000 & Rp12.090.000 \\
\hline Responden 22 & 1 & Rp2.795.000 & Rp16.200.000 & Rp13.405.000 \\
\hline Responden 23 & 1 & Rp1.670.000 & Rp12.600.000 & Rp10.930.000 \\
\hline Responden 24 & 1 & Rp1.550.000 & Rp14.400.000 & Rp12.850.000 \\
\hline Responden 25 & 1 & Rp3.500.000 & Rp10.800.000 & Rp7.300.000 \\
\hline Responden 26 & 1 & Rp1.800.000 & Rp16.200.000 & Rp14.400.000 \\
\hline Responden 27 & 0,25 & Rp1.962.000 & Rp8.640.000 & Rp6.678.000 \\
\hline Responden 28 & 0,5 & Rp3.034.000 & Rp9.360.000 & Rp6.326.000 \\
\hline Responden 29 & 2 & Rp545.000 & Rp15.120.000 & Rp14.575.000 \\
\hline Responden 30 & 0,3 & Rp5.080.000 & Rp10.800.000 & Rp5.720.000 \\
\hline Rata-Rata & 0,94 & Rp3.473.800 & Rp11.787.667 & Rp8.313.867 \\
\hline
\end{tabular}

Sumber: Data primer diolah

Tabel diatas menggambarkan besaran total luas lahan, total biaya,serta total keuntungan petani padi di Desa Moyo Hilir Kecamatan Moyo Kabupaten Sumbawa. Dari tabel diatas ditemukan bahwa luas lahan terendah responden adalah 20 are (0,2 ha) sedangkan yang 
tertinggi adalah 8 ha. Adapun rata-rata luas lahan petani adalah 0,94 ha. Angka ini lebih tinggi dari rata-rata luas lahan pertanian yang dikuasai petani di tingkat nasional maupun di tingkat Provinsi NTB. BPS (2013) melalui Sensus Pertanian mengungkap rata-rata luas lahan pertanian yang dikuasai petani di Indonesia adalah 0,85 ha, sedangkan untuk Provinsi NTB, luas lahan pertanian rata-rata adalah 0,64 ha. Adapun total biaya dalam tabel diatas merupakan penjumlahan dari seluruh biaya yang dikeluarkan petani dalam usahatani padinya. Berdasarkan tabel diatas, dapat diketahui bahwa total biaya yang dikeluarkan petani sangat variatif mengingat luas lahan yang diusahakan serta tingkat keterampilan bertani yang dimiliki petani berbeda antara petani yang satu dengan petani yang lainnya. Secara rata-rata, total biaya yang dikeluarkan petani adalah Rp 3.473.800. Sementara itu, penerimaan total (revenue) dalam tabel diatas dihitung dengan menggunakan formula:

$$
\mathrm{TR}=\mathrm{P} X \mathrm{Q}
$$

dimana,

$\mathrm{P} \quad=$ Harga jual gabah petani

Q $\quad=$ Jumlah gabah yang dihasilkan petani

Sama halnya dengan total biaya yang variatif, total penerimaan setiap petani juga berbeda-beda karena adanya perbedaan luas lahan yang diusahakan, kemampuan bertani, serta kemampuan mengakses pasar. Secara rata-rata, total penerimaan yang didapatkan petani dari usahatani padi di Desa Moyo Hilir adalah Rp 11.787.667 sehingga total keuntungan faktual yang diterima mencapai Rp 8.313.867.Mengingat bahwa usia panen tanaman padi adalah 4 bulan, makakeuntungan bulanan yang diterima petani sebenarnya adalah Rp2.078.466. Penting untuk diingat kembali bahwa biaya tetap berupa biaya sewa lahan belum dihitung dalam data diatas sehingga keuntungan faktual yang diterima petani sesungguhnya lebih rendah dari angka tersebut jika komponen biaya tetap itu diperhitungkan.

Data diatas mampu menjelaskan secara faktual besarnya nilai keuntungan petani padi di Desa Moyo Hilir namun tidak dapat menggambarkan tingkat produktifitas usahatani padi di desa tersebut. Hal ini karena jauhnya perbedaan luas lahan pertanian yang diusahakan setiap petani yang menjadi responden. 


\section{Garis Kemiskinan}

Berdasarkan konsep-konsep garis kemiskinan, kita dapat mengetahui apakah para petani di Desa Moyo Hilir masuk dalam kategori miskin atau tidak jika kebutuhan sehari-hari mereka seluruhnya dipenuhi dari hasil usahatani padi. Sebagai acuan, kita perlu menghitung garis kemiskinan bulanan berdasarkan konsep-konsep diatas sebagaimana dituliskan sebagai berikut:

$$
\begin{aligned}
\text { GKWB } & =(e \times 1,90) \times 30 \\
& =(\operatorname{Rp} 13.300 \times 1,90) \times 30 \\
& =\operatorname{Rp} 758.100
\end{aligned}
$$

dimana,

GKWB = Garis Kemiskinan World Bank

$e \quad=$ Nilai tukar Dolar Amerika terhadap Rupiah Indonesia

Berdasarkan perhitungan diatas, acuan garis kemiskinan menurut World Bank adalah Rp 758.100,- per kapita per bulan. Sedangkan acuan garis kemiskinan menurut sajogyo adalah:

$$
\begin{aligned}
G K S & =(P \times 320) / 12 \\
& =(\operatorname{Rp} 10.000 X 320) / 12 \\
& =\operatorname{Rp} 266.667
\end{aligned}
$$

dimana,

$$
\begin{array}{ll}
\text { GKS } & =\text { Garis Kemiskinan Sajogyo } \\
\mathrm{P} & =\text { Harga beras per kilogram di Sumbawa }
\end{array}
$$

Mengacu pada garis kemiskinan menurut World Bank dan Sajogyo tersebut, kita dapat mengetahui apakah petani padi di Desa Moyo Hilir termasuk dalam kategori miskin atau tidak. Jika penghasilan per kapita anggota keluarga petani kurang dari nilai garis kemiskinan diatas, maka petani dan anggota keluarganya tersebut termasuk dalam kategori miskin. Untuk mengetahui besarnya penghasilan per kapita anggota keluarga petani dari usahatani padi, diperlukan perhitungan dengan rumus berikut:

$$
\mathrm{I} / \text { kapita }=\frac{(\pi / T K)}{4}
$$

dimana,

$\mathrm{I} /$ kapita = Income atau pendapatan per kapita anggota keluarga per bulan

$\Pi \quad=$ Keuntungan faktual

TK = Jumlah tanggungan keluarga 
Berdasarkan rumus diatas, didapatkan nilai penghasilan perkapita anggota keluarga petani sebagaimana ditunjukkan oleh tabel berikut:

Tabel 2. Keuntungan Per Kapita dari Usahatani Padi di Desa Moyo Hilir

\begin{tabular}{|c|c|c|c|c|c|}
\hline Responden & 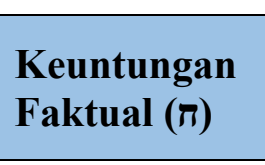 & $\begin{array}{l}\text { Tanggungan } \\
\text { Keluarga }\end{array}$ & $\begin{array}{l}\text { Pendapatan } \\
\text { Perkapita } \\
\text { Petani }\end{array}$ & $\begin{array}{l}\text { Lama } \\
\text { Usaha } \\
\text { (bulan) }\end{array}$ & $\begin{array}{l}\text { Pendapatan } \\
\text { / kapita / } \\
\text { bulan }\end{array}$ \\
\hline Responden 1 & Rp14.710.000 & 5 & Rp2.942.000 & 4 & Rp735.500 \\
\hline Responden 2 & Rp2.175.000 & 2 & Rp1.087.500 & 4 & Rp271.875 \\
\hline Responden 3 & Rp3.265.000 & 2 & Rp1.632.500 & 4 & Rp408.125 \\
\hline Responden 4 & Rp12.928.000 & 4 & Rp3.232.000 & 4 & Rp808.000 \\
\hline Responden 5 & Rp5.605.000 & 3 & Rp1.868.333 & 4 & Rp467.083 \\
\hline Responden 6 & Rp3.900.000 & 3 & Rp1.300.000 & 4 & Rp325.000 \\
\hline Responden 7 & Rp600.000 & 7 & Rp85.714 & 4 & Rp21.429 \\
\hline Responden 8 & Rp5.500.000 & 5 & Rp1.100.000 & 4 & Rp275.000 \\
\hline Responden 9 & Rp3.005.000 & 4 & Rp751.250 & 4 & Rp187.813 \\
\hline Responden 10 & Rp22.490.000 & 5 & Rp4.498.000 & 4 & Rp1.124.500 \\
\hline Responden 11 & Rp5.550.000 & 3 & Rp1.850.000 & 4 & Rp462.500 \\
\hline Responden 12 & Rp12.170.000 & 3 & Rp4.056.667 & 4 & Rp1.014.167 \\
\hline Responden 13 & Rp5.446.000 & 5 & Rp1.089.200 & 4 & Rp272.300 \\
\hline Responden 14 & Rp5.390.000 & 3 & Rp1.796.667 & 4 & Rp449.167 \\
\hline Responden 15 & Rp5.460.000 & 3 & Rp1.820.000 & 4 & Rp455.000 \\
\hline Responden 16 & Rp3.865.000 & 3 & Rp1.288.333 & 4 & Rp322.083 \\
\hline Responden 17 & Rp4.205.000 & 2 & Rp2.102.500 & 4 & Rp525.625 \\
\hline Responden 18 & Rp20.720.000 & 2 & Rp10.360.000 & 4 & Rp2.590.000 \\
\hline Responden 19 & Rp4.715.000 & 1 & Rp4.715.000 & 4 & Rp1.178.750 \\
\hline Responden 20 & Rp3.443.000 & 2 & Rp1.721.500 & 4 & Rp430.375 \\
\hline Responden 21 & Rp12.090.000 & 3 & Rp4.030.000 & 4 & Rp1.007.500 \\
\hline Responden 22 & Rp13.405.000 & 2 & Rp6.702.500 & 4 & Rp1.675.625 \\
\hline Responden 23 & Rp10.930.000 & 5 & Rp2.186.000 & 4 & Rp546.500 \\
\hline Responden 24 & Rp12.850.000 & 6 & Rp2.141.667 & 4 & Rp535.417 \\
\hline Responden 25 & Rp7.300.000 & 3 & Rp2.433.333 & 4 & Rp608.333 \\
\hline Responden 26 & Rp14.400.000 & 4 & Rp3.600.000 & 4 & Rp900.000 \\
\hline Responden 27 & Rp6.678.000 & 4 & Rp1.669.500 & 4 & Rp417.375 \\
\hline Responden 28 & Rp6.326.000 & 4 & Rp1.581.500 & 4 & Rp395.375 \\
\hline Responden 29 & Rp14.575.000 & 5 & Rp2.915.000 & 4 & Rp728.750 \\
\hline Responden 30 & Rp5.720.000 & 3 & Rp1.906.667 & 4 & Rp476.667 \\
\hline Rata-Rata & Rp8.313.867 & 4 & Rp2.615.444 & 4 & Rp653.861 \\
\hline
\end{tabular}

Sumber: data primer diolah

Tabel diatas menunjukkan bahwa rata-rata pendapatan per kapita per bulan petani padi di Desa Moyo Hilir adalah Rp 653.861,-. Perlu diingat bahwa penghasilan tersebut merupakan 
penghasilan bulanan dari usahatani padi semata, sedangkan penghasilan dari sumber lainnya tidak dihitung. Jika petani padi di Desa Moyo hanya mendapatkan penghasilan dari usahatani padi, maka secara rata-rata petani padi Moyo termasuk kategori miskin menurut Bank Dunia karena penghasilan per kapita per bulan mereka lebih rendah dari garis kemiskinan sebesar Rp758.100,-. Akan tetapi jika mengacu pada garis kemiskinan sajogyo, maka keluarga petani padi di Desa Moyo tidak termasuk dalam kategori miskin karena penghasilan bulanan per kapita mereka lebih besar dari garis kemiskinan versi sajogyo yakni sebesar Rp266.667,-Meski konsep dasar garis kemiskinan mengacu pada besarnya jumlah pengeluaran, sementara data yang tersedia merupakan data pendapatan, namun dalam penelitian ini diasumsikan bahwa seluruh biaya yang dikeluarkan petani dan keluarganya untuk memenuhi kebutuhan hidup sehari-hari bersumber dari pendapatan usahatani padi.

Secara rinci, besarnya jumlah petani yang termasuk kategori miskin menurut Bank Dunia maupun Sajogyo di Desa Moyo Hilir dapat dilihat pada tabel berikut:

Tabel 3. Jumlah dan prosentase petani padi miskin di Desa Moyo Hilir

\begin{tabular}{|c|l|l|c|c|}
\hline No & Garis Kemiskinan & \multicolumn{1}{|c|}{ Kriteria } & $\begin{array}{c}\text { Jumlah } \\
\text { (orang) }\end{array}$ & $\begin{array}{c}\text { Prosentase } \\
\text { (\%) }\end{array}$ \\
\hline \multirow{2}{*}{1} & Bank Dunia & Miskin & 22 & 73,3 \\
\cline { 3 - 5 } & & Tidak Miskin & 8 & 26,7 \\
\cline { 3 - 5 } & Sajogyo & Miskin & $\mathbf{3 0}$ & $\mathbf{1 0 0}$ \\
\cline { 3 - 5 } & Tidak Miskin & 2 & 6,7 \\
\cline { 3 - 5 } & Total & $\mathbf{3 0}$ & 93,3 \\
\hline
\end{tabular}

Sumber: data primer diolah

Berdasarkan tabel diatas, diketahui bahwa jumlah petani padi yang berada dibawah garis kemiskinan Bank Dunia di Desa Moyo Hilir adalah 22 orang atau setara dengan 73,3\%, sementara menurut garis kemiskinan Sajogyo, petani padi yang tergolong miskin hanya 6,7\% atau 2 orang saja. 


\section{E. Kesimpulan}

Berdasarkan uraian diatas, dapat ditarik kesimpulan sebagai berikut:

1. Total keuntungan faktual rata-rata petani padi di Desa Moyo Hilir adalah Rp8.313.867,selama satu periode tanam atau setara dengan Rp2.078.467,- per bulan. Sementara itu total keuntungan rata-rata per hektar tanaman padi adalah Rp13.360.746,- per musim tanam atau setara dengan Rp3.340.186,- per bulan.

2. Rata-rata total pendapatan per kapita per bulan keluarga petani dari usahatani padi di Desa Moyo Hilir adalah Rp653.861,-. Angka ini lebih rendah dari nilai garis kemiskinan menurut Bank Dunia yakni Rp758.100,- tetapi lebih tinggi dari garis kemiskinan Sajogyo sebesar Rp266.667,-. Adapun jumlah petani padi yang berada dibawah garis kemiskinan menurut Bank Dunia adalah 22 orang atau 73,3\%, sedangkan jumlah petani padi miskin menurut indikator garis kemiskinan Sajogyo adalah 2 orang atau $6,7 \%$.

\section{DAFTAR PUSTAKA}

Agusta, Ivanovic. 2016. Setelah Garis Kemiskinan Sajogyo. Working Paper di Institut Pertanian Bogor (IPB).

Badan Pusat Statistik (BPS). 2012. Kecamatan Dalam Angka Tahun 2012. Sumbawa : Badan Pusat Statistik.

Badan Pusat Statistik (BPS). 2016. Statistik Pertanian Indonesia. Jakarta : Badan Pusat Statistik.

Bank Dunia. 2016. World Development Indikator: Poverty and Inequality. [internet] http://datatopics.worldbank.org

Arsyad, Lincolin. 2005. An Assesment of Microfinance Institution Performance : The Importance of Institutional Environment. Gadjah Mada International Journal of Business 7(3) : $391-472$.

Fatmawati, M. Lumintang. 2013. Analisis Pendapatan Petanu Padi di desa Tetep Kecamatan Langowan Timur. Jurnal EMBA Vol 1 No.3 September 2013

Haryanto T, Hidayati NA, Djoewito W. 2009. Ekonomi Peranian. Surabaya: Airlangga University Press.

Kuncoro, Mudrajad. 2004. Otonomi Dan pembangunan Daerah: Reformasi, Perencanaan, Strategi dan Peluang. Erlangga. Jakarta. 
Laila, Nor dkk. Analisis Pendapatan Usahatani Padi (Oryza sativa L.) benih Varietas Ciherang yang Bersetifikat dan Tidak Bersertifikat di Kecamatan Labuan Amas Selatan Kabupaten Hulu Sungai Tengah. Media SainS, Volume 4 Nomor 1, April 2012.

Nasir. Moh 2003. Metode Penelitian. Ghalian Indonesia.

Nurjihadi, Muhammad. Lingkaran Setan Kemiskinan Pada Masyarakat Pedesaan, Studi Kasus Petani Tembakau Virginia di Pulau Lombok. Jurnal Sodality Volume 4 Nomor 2, Desember 2016.

Sukirno, S. 2004. Pengantar Teori Mikro Ekonomi. Raja Grafindo Persada. Jakarta.

Supartama, Made dkk. 2013. Analisis Pendapatan dan Kelayakan Usahatani Padi Sawah di Subak Baturiti Desa Balinggi Kecamatan Balinggi Kabupaten Parigi Moutong. E Jurnal Agrotekbis 1(2) : 166-172, Juni 2013. 